\title{
Differential Pathology of Capripox Isolates in Chicken Embryonated Eggs
}

\author{
Sankalp Sharma ${ }^{1 *}$, Nawab Nashiruddullah ${ }^{1}$, Jafrin Ara Ahmed ${ }^{2}$ and Sindhu Berian ${ }^{3}$ \\ ${ }^{1}$ Division of Veterinary Pathology, Faculty of Veterinary Sciences and Animal Husbandry, \\ Sher-e-Kashmir University of Agricultural Science and Technology of Jammu, RS Pura- \\ 181102, India \\ ${ }^{2}$ Division of Veterinary Physiology \& Biochemistry, Faculty of Veterinary Sciences and \\ Animal Husbandry, Sher-e- Kashmir University of Agricultural Science and Technology of \\ Jammu, RS Pura-181102, India \\ ${ }^{3}$ Division of Veterinary Medicine, Faculty of Veterinary Sciences and Animal Husbandry, \\ Sher-e- Kashmir University of Agricultural Science and Technology of Jammu, RS Pura- \\ 181102, India
}

*Corresponding author

\section{A B S T R A C T}

\section{Keywords}

Capripox,

Histopathology,

Chorioallantoic

Membrane (CAM),

Chicken

Embryonated Eggs

(CEE)

Article Info

Accepted:

22 July 2019

Available Online:

10 August 2019

During various Capripox outbreaks in Jammu region, either sheep or goats were found to be affected separately by the disease showing the characteristic cutaneous lesions. Even when both sheep and goats were reared together, the disease was restricted to either host only. Clinical scab samples obtained from both sheep and goats were designated as putative Sheep poxvirus (SPPV) and Goatpoxvirus (GTPV). The isolates were processed and inoculated on the chorioallantoic membrane (CAM) of chicken embryonated eggs (CEE) to study the growth characteristics of the isolates. While sheep isolates failed to grow on chorioallantoic membrane (CAM) of chicken embryonated eggs (CEE), goat isolates showed haemorrhages and thickening of membrane with presence of white pock lesions after 2-3 serial passages. Histological examination of the affected CAM showed degeneration of the ectodermal layer together with vacoulation of cells. There were areas of necrosis and presence of eosinophilic intracytoplasmic inclusion bodies within the stromal cells. The putative isolates were confirmed as belonging to SPPV and GTPV genotypes after nucleotide sequencing of partial P32 core protein gene. It is assumed that the differential growth characteristics of the isolates may be an indication of strain variability. Further it is inferred that the non-ability to grow in CEE cannot be used as a criterion either to negate the diagnosis of CaPV, nor the differentiation between SPPV and GTPV.

\section{Introduction}

Capripoxvirus (CaPV) of small ruminants are most severe of the pox diseases of domestic animals, and they have a very important role in agricultural economy. They are included in the list of notifiable diseases of Office International des Epizooties (OIE). Sheep pox and goat pox are highly contagious viral diseases of sheep and goat which are caused 
by the epitheliotropic DNA pox viruses of genus Capripoxvirus, subfamily Chordopoxvirinae and the family Poxviridae. Sheeppoxvirus (SPPV), Goatpoxvirus (GTPV) and Lumpy skin disease virus (LSDV) are members of this genus that are believed to be host specific, i.e. while SPPV and GTPV affect sheep and goat respectively, LSDV causes disease in cattle.

Isolation of $\mathrm{CaPV}$ in embryonated chicken eggs (CEE) is considered to be a preliminary diagnostic test (Kadam et al., 2013) associated with the development of characteristic pock lesions when inoculated on the chorioallantoic membrane (CAM). For the first time GTPV has been cultivated successfully in developing chicken embryos by Bakos and Brag (1957).

Sometimes they pose difficulty in isolation or may differ significantly in their growth behaviour in embryonated chick eggs, as has been observed with GTPV (Mohamed et al., 1982; Bandyopadhyay et al., 1984) or SPPV isolates (Adlakha et al., 1971; Tantawi and Al-Falluji, 1979; Rao and Bandyopadhyay, 2000). On the other hand, various studies suggest the successful isolation of SPPV alone (Dutta et al., 2002; Khameis et al., 2018) or together with GTPV (Mahmoud and Khafagi, 2016).

During screening of small ruminants from various districts of Jammu region, both goat and sheep were found to be affected with Capripox infection (Sharma, 2019). Interestingly, the disease was restricted to either host only, even when both sheep and goats were reared together. The isolates from affected sheep were designated as SPPV, while those from affected goats were designated as GTPV. The putative isolates of SPPV and GTPV were processed and inoculated in CEE to examine their differential pathology.

\section{Materials and Methods}

In the present study, suspected samples of Capripoxvirus infection were collected from various organized and unorganized farms from Jammu region covering nine districts (except Ramban district). Samples were collected at different times from June 2017 to November 2018.

\section{Isolation of putative CaPV (SPPV, GTPV) from clinical samples}

Clinical scab/skin samples of affected animals were processed for virus isolation. A $10-20 \%$ solution of the scab samples in PBS was prepared by mechanical homogenization using a sterilized mortar and pestle. Homogenized samples were centrifuged at $3,000 \times \mathrm{g}$ for $15 \mathrm{~min}$. The supernatant was then passed through a $0.45 \mu \mathrm{m}$ syringe filter (Millipore) and incubated with streptomycin, penicillin antibiotic solution (@ 200 IU of penicillin and $200 \mu \mathrm{g}$ of streptomycin per $\mathrm{ml}$ suspension for $1 \mathrm{hr}$ at $37^{\circ} \mathrm{C}$. Processed samples were used for infecting CAM for virus isolation.

\section{Chicken embryonated eggs (ECE)}

Approximately 10-12 day old embryonated chicken eggs from Government Poultry Hatchery Unit, Belicharana, under Animal Husbandry Department, Jammu were procured for virus inoculation.

\section{Chorio-Allantoic Membrane inoculation of virus}

For virus isolation in CAM, the protocol described in Cunningham (1973) by the artificial air sac route was employed. Briefly-

Embryos of 10-12 days of age were candled for embryo viability.

An area was marked about 1/4 inch below and 
parallel to the base of the air cell and disinfected.

A hole was drilled at this mark being very careful not to tear the shell membrane, and another was drilled directly at the top of the air cell.

The embryo was placed horizontally with the hole facing up.

Holding the embryo in the same position and using a rubber bulb, air was drawn out of the air cell by placing the bulb over the hole at the top of the embryo. This negative pressure created the artificial air cell by pulling the CAM down.

A fine gauge needle (tuberculin syringe) was inserted into the artificial air sac about $1 / 8$ inch and $0.1 \mathrm{ml}$ inoculum released.

The embryo was laid horizontally for 24 hours then returned to upright position.

The holes in the inoculated eggs were sealed with molten wax and were incubated for five days at $37^{\circ} \mathrm{C}$ in an egg incubator. After 5-6 days of inoculation, eggs were opened to separate CAM from the embryo.

Both putative SPPV and GTPV were inoculated on CAM. Mock inoculation with sterile Phosphate buffered saline (PBS) served as negative control.

\section{Histopathological examination}

Embryonated chicken egg CAM was processed for histopathological examination. Tissue samples were preserved in $10 \%$ buffered formalin. All procedures were adopted from Luna (1968). Processing was done by routine alcohol-xylene dehydration and clearing. Embedding was done by low melting paraffin wax. Tissue sectioning was done at 4-5 micron thickness with a rotary microtome. Sections were stained with routine Harris haematoxylin and eosin stains and mounted with DPX for observing the histomorphological changes.

\section{Results and Discussion}

Virus inoculation in embryonated egg

In the chicken embryonated egg inoculation, out of the the various field samples, putative GTPV and SPPV were adopted on CAM in 10-12 days chicken emryonated eggs which were opened on the $5^{\text {th }}$ day post inoculation. The results of virus inoculation in CEE are summarized in Table 1.

\section{Sheep}

No lesions were observed on CAM with putative Sheeppoxvirus (SPPV) isolate even after $3^{\text {rd }}$ passage in CEE observed after 5 days of inoculation.

\section{Goat}

The lesions on the CAM with putative Goatpoxvirus (GTPV) isolate in the first passage were characterized by the opaque thickening and oedema of the membrane. Haemorrhages were also observed on the membrane.

On subsequent second and third passage level, there was presence of small, round, white circular lesions or 'pocks' distinctly visible on the membrane (Fig. 1A). The size of the pocks were approximately $1-3 \mathrm{~mm}$ in diameter.

\section{Negative control}

No lesions were observed in control CEE incubated at each parallel passage level.

Histological examination of the affected CAM showed degeneration of the ectodermal layer together with vacoulation of cells. There were areas of necrosis and presence of eosinophilic intracytoplasmic inclusion bodies within the stromal cells (Fig. 1B). 
Fig.1 Virus inoculation on Chorio-Allantoic Membrane (CAM) of Chicken Embryonated Egg (CEE). (A) Pock lesions (arrow) on CAM after second passage with Capripox clinical isolate from goat; (B) Microscopic lesions of 'A' showing presence of eosinophilic intracytoplasmic inclusion bodies (arrow) within the stromal cells

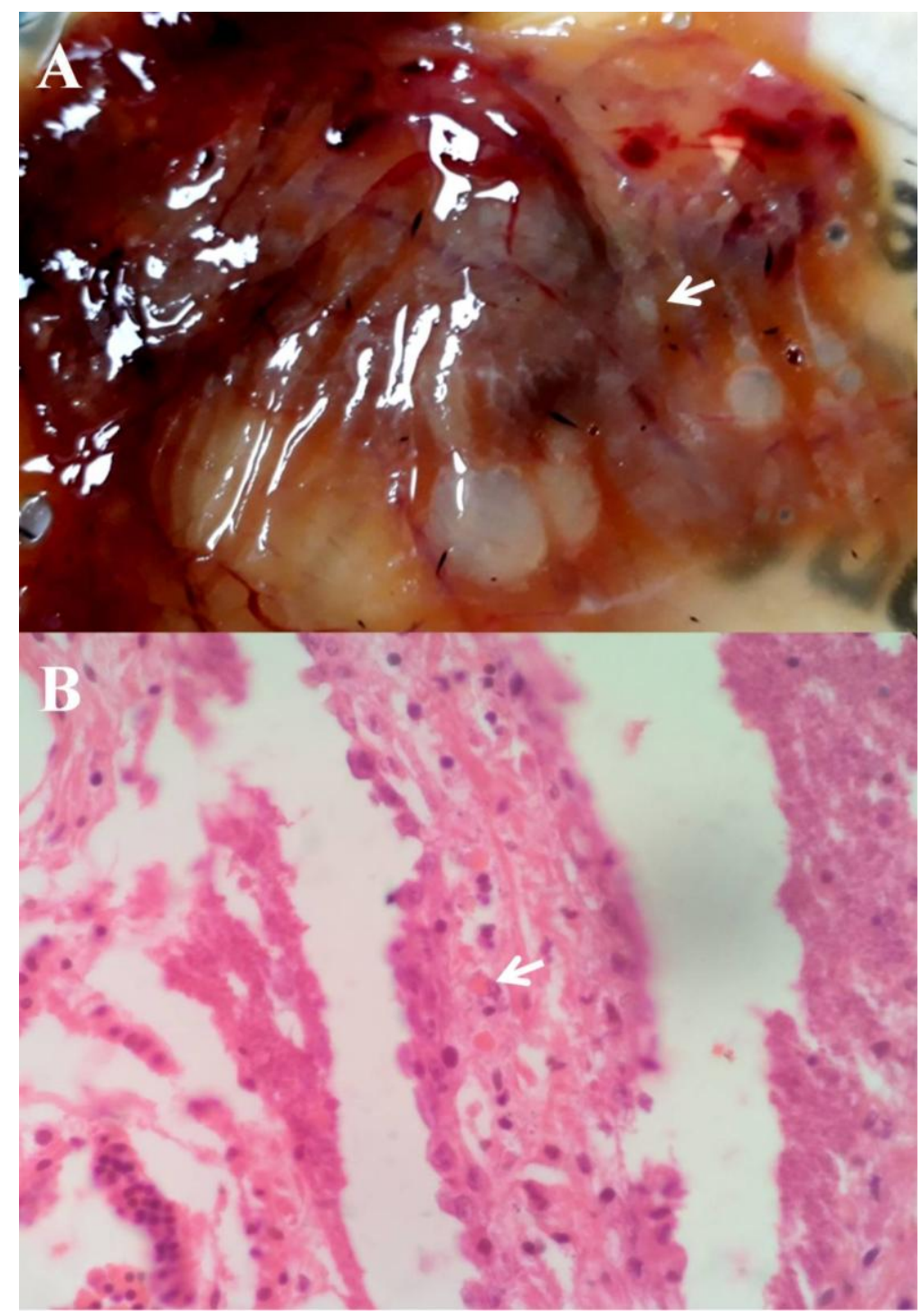

Attempts to inoculate with clinical materials from sheep (putative Sheeppoxvirus) failed to yield any lesions on CAM. These results are in agreement with many earlier workers that failed to propagate the virus in CEE (Sen and Uppal, 1972; Bhatnagar and Gupta, 1974; Mahmoud et al., 2016) including up to six repeated passages (Davies, 1976). Contrarily, Aswini (2015) observed embryonic mortality, oedema, haemorrhages and necrosis after 2-7 days post-inoculation.
Inoculation with goat isolates (putative Goatpoxvirus) in the present study showed embryo mortality and apparent pock lesions in $2^{\text {nd }}$ to $3^{\text {rd }}$ passage. Mortality, oedema and haemorrhages have also been described by others (Prakash et al., 1995; Batta et al., 1999; Verma et al., 2011; Kumar et al., 2014; Jayasri, 2015) with GTPV; while pock lesions have been described by some (Tantawi and Al-Falluji, 1979; Verma et al., 2011; Kadam et al., 2013). However, many have failed to 
isolate goatpox virus in CEE (Mohamed et al., 1982; Bandyopadhyay et al., 1984). It is postulated that GTPV's ability to grow on CEE varies considerably depending on strains of the virus (Joshi et al., 1992); and that some strains like Mukteswar (Adlakha et al., 1971) and Dushanbe (Tantawi and Al-Falluji, 1979) does not grow at all.

Microscopically, the ectodermal lining of the CAM showed degeneration and vacuolation of the cells in all the passages. Necrotic areas and a few intracytoplasmic, eosinophilic inclusions were also seen in ectoderm on $3^{\text {rd }}$ passage. Joshi et al., (1996) using the Sambalpur (India) strain of GTPV similarly noticed marked proliferation in the ectodermal layer and presence of intracytoplasmic acidophillic inclusion that were confirmed by electron microscopy to contain typical pox virus particles.

The Capripoxvirus isolates (putative SPPV and GTPV) from the present study were confirmed later by partial amplification of the P32 core protein gene, and speciation of the isolates was confirmed as SPPV and GTPV by sequencing and multiple nucleotide alignment with notified genogroups (data not shown).

From the present study it could be concluded that strains of the virus may differ in their ability to grow in embryonated eggs and their differential growth may therefore be an indication of strain variability. However, the non-ability to grow in CEE cannot be used as a criterion either to negate the diagnosis of CaPV, nor the differentiation between SPPV and GTPV.

\section{References}

Adlakha, S.C., Bansal, M.P. and Malik, B.S. 1971. Studies on sheep and goat poxviruses. Adaptation of the viruses in laboratory animals and tissue culture.
Indian J. Anim. Sci. 41: 171-175.

Aswini, B.S. 2015. Pathological and molecular diagnosis of sheep pox. MVSc thesis submitted to Sri Venkateswara Veterinary University, Tirupati, Andhra Pradesh, India.

Bakos, K. and Brag, S. 1957. Studies of goat pox in Sweden. Nordisk Veterinaermedicin. 9: 431-439.

Bandyopadhyay, S.K., Gajendragad, M.R., Dhal, K., Gupta, A.R. and Yadav, M.P. 1984. Some observations on a goat-pox virus isolated from an outbreak in Orissa. Indian J. Anim. Sci. 54(10): 961-964.

Batta, M.K., Katoch, R.C., Sharma, M., Joshi, V.B. and Nagal, K.B. 1999. Epidemiological observation on goat pox in Himachal Pradesh. Indian Vet J. 76: 683-684.

Bhatnagar, A. and Gupta, B.M. 1974. Affinity of sheep pox virus (SP8 strain) for heterologous system. Curr. Sci. 43: 254255.

Cunningham, C.H. 1973. A Laboratory Guide in Virology. $7^{\text {th }}$ Edition. Burgess Publishing Co., Minneapolis, Minnesota.

Davies, F.G. 1976. Characteristics of a virus causing a pox disease in sheep and goats in Kenya, with observations on the epidemiology and control. J. Hyg. Cambridge Univ. 76: 163-171.

Dutta, T.K., Sentil Kumar, V.S., Raina, A.K., Singh, R. and Wazir, V.S. 2002. An outbreak of sheep pox disease in an organized farm of Jammu and Kashmir. Indian J. Comp. Microbiol. Immunol Infect. Dis. 23(2): 183-184.

Jayasri, K. 2015. Pathological and molecular diagnosis of goatpox. MVSc thesis submitted to Sri Venkateswara Veterinary University, Tirupati, Andhra Pradesh, India.

Joshi, R.K., Chandra, R., Rao, V.D.P. and Garg, S.K. 1992. Goatpox: A review. J. Appl. Anim. Res. 2: 57-72.

Joshi, R.K., Garg, S.K., Chandra, R. and Sharma, S.N. 1996. Growth behaviour of Sambalpur strain of goat pox virus on chorioallantoic membrane of developing chicken embryo. Indian J. Virol. 12: 109111. 
Kadam, A.S., Tembhurne, P.A., Ingle, V.C., Kumar, P.M., Dhok, A.K., Kalorey, D.R. Koylu, A. and Nitzschke, E. 1968. Characterstics of sheep and goat pox viruses from Turkey- I. Studies on thermostability. Pendik Inst. Vet.Control, 1: 57-65.

Kadam, A.S., Tembhurne, P.A., Ingle, V.C., Kumar, P.M., Dhok, A.K. and Kalorey, D.R. 2013. Detection of sheep and goat pox viruses by Polymerase Chain Reaction. Indian J. Field Vet., 9(3): 48-51.

Khameis, A.S., Atteya, L.F., Mansour, A.H., Abdelhady, H.A. and Saad, A.A. 2018. Molecular detection and phylogenetic analysis of sheep pox virus in El Menofiya Governorate. J. Virol. Sci. 3: 49- 57.

Kumar, A., Hirpurkar, S.D., Sannat, C. and Gilhare, V.R. 2014. Isolation of goat pox virus from Durg district of Chhattisgarh. $J$. Small Ruminants. 20(2): 141-144.

Luna, L.G. 1968. Manual of Histological Staining Methods of the Armed Forces Institute of Pathology, $3^{\text {rd }}$ Edn. McGraw Hill Book Co., New York.

Mahmoud, A.Z.E., Khalafalla, A.I. and Abdellatif, M.M. 2016. An epidemiological study of sheep and goat pox outbreaks in the Sudan. Food Biol. 5: 1-5.

Mahmoud, M.A. and Khafagi, M.H. 2016. Detection, identification and differentiation of sheeppox virus and goatpox virus from clinical cases in Giza Governorate, Egypt. Vet. World. 9(12): 1445-1449.

Mohamed, K.A., Hago, B.E., Taylor, W.P., Nayil, A.A. and Abu-Shmra, M.T. 1982. Goat pox in the Sudan. Trop. Anim. Hlth. Prod. 14(2):104-108.

Prakash, V., Chandra, R., Rao, V.D.P. and Garg, S.K. 1995. Cultivation of goat pox virus in developing chicken embryo. Indian $J$. Anim. Sci. 65(1): 28-30.

Rao, T.V. and Bandyopadhyay, S.K. 2000. A comprehensive review of goat pox and sheep pox and their diagnosis. Anim. Hlth. Res. Rev. 1: 127-36.

Sen, A.K. and Uppal, P.K. 1972. Adapation of sheep-pox virus in embryonated eggs. Indian J. Anim. Sci. 42:427.

Sharma, S. 2019. Pathology and characterization of pox virus infection of small ruminants in Jammu region. $\mathrm{PhD}$ Thesis submitted to Sher-e- Kashmir University of Agricultural Science and Technology of Jammu, India.

Tantawi, H.H. and Al-Falluji, M.M. 1979. Laboratory characteristics of four strains of goat pox virus. Acta Virol. 23(6): 455-60.

Verma, S., Verma, L.K., Gupta, V.K., Katoch, V.C., Dogra, V., Pal, B. and Sharma, M. 2011. Emerging Capripoxvirus disease outbreak in Himachal Pradesh, a Northern state of India. Transbound. Emerg. Dis. 58: $79-85$

\section{How to cite this article:}

Sankalp Sharma, Nawab Nashiruddullah, Jafrin Ara Ahmed and Sindhu Berian. 2019. Differential Pathology of Capripox Isolates in Chicken Embryonated Eggs. Int.J.Curr.Microbiol.App.Sci. 8(08): 2485-2490. doi: https://doi.org/10.20546/ijcmas.2019.808.289 